\title{
Replantation surgery in Quebec: The bottlenecks to rapid care
}

\author{
Daniel E Borsuk BSc ${ }^{1,2}$, Teanoosh Zadeh MD FRCSC ${ }^{2,3}$, Chen Lee MD MSc FRCSC FACS, \\ Karl Moore MBA MA (Oxon) PhD CPMI ${ }^{2}$, Grace Tan BSc (Pharm) MSc DPhil (Oxon) ${ }^{1}$
}

DE Borsuk, T Zadeh, C Lee, K Moore, G Tan. Replantation surgery in Quebec: The bottlenecks to rapid care. Can J Plast Surg 2006;14(3):155-157.

INTRODUCTION: Time delays resulting in prolonged ischemia have a significant impact on the successful reattachment of amputated body parts. No studies have addressed the issues surrounding delays from the time of the accident to the start of replantation surgery. The present paper identifies the bottlenecks that prolong the time before patients are able to gain access to a replant team.

METHODS: A total of 50 patients underwent microsurgical replantation, because of traumatic amputation, at a university-based hospital from 1996 to 2003. The charts were analyzed to ascertain individual time intervals from the onset of injury until the beginning of replant surgery.

RESULTS: The average length of time for patients who came directly to the replant centre was 3 h 40 min before surgery began. In contrast, for those referred from outlying hospitals, the elapsed time was $6 \mathrm{~h} 21 \mathrm{~min}$.

CONCLUSIONS: Two major bottlenecks were found. First, for patients who were referred from other health centres, delays were due to a lack of information as to where patients could receive appropriate replant surgery. Second, delays at the replant centre were primarily due to insufficient physical and human resources in the operating room.

Key Words: Amputation; Replant surgery; Time delays

Trauma surgeons have long held the belief that a decrease in the time between injury and definitive care improves outcome (1). Patients directly admitted to a trauma centre have a shorter length of stay and fewer health care costs (2); in addition, there may be a reduced risk for overall mortality and morbidity (3). A previous study (1) has made the same conclusions with respect to trauma patients from rural areas. Others argue that while mortality and length of stay were similar, total costs were significantly greater for transferred patients (4). In the case of replantation surgery, time delays resulting in prolonged ischemia had a significant impact on the successful reattachment of the amputated body part (5).

In 1995, patient triage and transfer protocols were implemented in Quebec for certain traumatic injuries (6). Despite the improvements, replantation protocols had not been established and specific guidelines had yet to be outlined for both primary hospital and prehospital care. Furthermore, no studies have addressed the issues surrounding delays from the time of the accident to the start of replantation surgery. In the present

\section{La chirurgie de regreffage au Québec : Les freins à des soins rapides}

HISTORIQUE : Les délais provoquant une ischémie prolongée ont de graves répercussions sur la réussite du regreffage de membres amputés. Il n'existe pas de protocole de regreffage, et aucunes lignes directrices précises n'ont encore été formulées, tant pour les soins primaires en milieu hospitalier que pour les soins avant l'arrivée à l'hôpital. Aucune étude ne porte sur les enjeux entourant le délai entre l'accident et le début de la chirurgie de regreffage. Le présent article précise les obstacles qui prolongent la période avant que les patients puissent accéder à une équipe de regreffage.

MÉTHODOLOGIE : Cinquante patients ont subi un regreffage microchirurgical par suite d'une amputation traumatique dans un certain hôpital universitaire entre 1996 et 2003. Les dossiers ont été analysés pour constater le délai entre chaque blessure et le début de la chirurgie de regreffage.

RÉSULTATS : Le délai moyen pour les patients qui venaient directement au centre de regreffage était de 3 h 40 avant le début de l'opération. Par contre, ceux qui étaient orientés par des hôpitaux excentriques attendaient $6 \mathrm{~h} 21$.

CONCLUSIONS : On a constaté deux freins principaux. D'abord, chez les patients orientés par d'autres centres de santé, les délais étaient causés par le manque d'information sur le lieu où les patients pouvaient subir un regreffage convenable. Ensuite, les délais au centre de regreffage étaient principalement attribuables au manque de ressources matérielles et d'effectifs dans la salle d'opération.

\footnotetext{
${ }^{1}$ Faculty of Medicine; ${ }^{2}$ Faculty of Managment; ${ }^{3}$ Division of Plastic Surgery; McGill University, Montreal, Quebec

Correspondence and reprints: Mr Daniel Borsuk, 2128 Fulton Road, Montreal, Quebec H3R 2L4. Telephone 514-296-6899, fax 514-738-7796, e-maildborsuk@gmail.com
} 
TABLE 1

Results for patients who were referred to the replantation centre from peripheral institutions

\begin{tabular}{|c|c|c|c|c|}
\hline & Referral & Maximum & Minimum & SD \\
\hline Time of accident to time of arrival at the referring hospital emergency room, h:min (mean) & $0: 34$ & $1: 25$ & 0:09 & $0: 18$ \\
\hline Time of arrival in the referring hospital emergency room to time of transfer to the replant centre by ambulance, h:min (mean) & $2: 12$ & $6: 15$ & $0: 45$ & $1: 25$ \\
\hline Duration of transport by ambulance to replant centre's emergency room, h:min (mean) & $0: 59$ & $2: 40$ & $0: 10$ & $0: 39$ \\
\hline Total delay to Montreal General Emergency Room (Montreal, Quebec), h:min (mean) & $3: 46$ & $7: 15$ & $1: 15$ & $1: 48$ \\
\hline Time of arrival in replant centre's emergency room to start time of anesthesia, h:min (mean) & $2: 35$ & $5: 35$ & $0: 20$ & $1: 24$ \\
\hline Mean total delay, h:min & $6: 21$ & $13: 05$ & 4:06 & $2: 05$ \\
\hline
\end{tabular}

TABLE 2

Results for patients who came directly to the replantation centre

\begin{tabular}{|c|c|c|c|c|}
\hline & To centre & Maximum & Minimum & SD \\
\hline Time of accident to time of arrival at the referring hospital emergency room & $\mathrm{N} / \mathrm{A}$ & $\mathrm{N} / \mathrm{A}$ & $\mathrm{N} / \mathrm{A}$ & N/A \\
\hline Time of arrival in the referring hospital emergency room to time of transfer to the replant centre by ambulance & $\mathrm{N} / \mathrm{A}$ & $\mathrm{N} / \mathrm{A}$ & $\mathrm{N} / \mathrm{A}$ & N/A \\
\hline Duration of transport by ambulance to replant centre's emergency room & N/A & $\mathrm{N} / \mathrm{A}$ & N/A & N/A \\
\hline Total delay to Montreal General Emergency Room (Montreal, Quebec), h:min (mean) & $0: 36$ & $1: 15$ & $0: 05$ & $0: 20$ \\
\hline Time of arrival in replant centre's emergency room to start time of anesthesia, h:min (mean) & 3:03 & 5:00 & $1: 10$ & 1:05 \\
\hline Mean total delay, h:min & $3: 40$ & $5: 45$ & $2: 25$ & 1:11 \\
\hline
\end{tabular}

N/A Not available

of the patient population being served by the centre and to help account for the time delays of the transfers.

\section{RESULTS}

There were 50 cases in the tertiary trauma centre that were coded 'traumatic amputations' in the hospital registry. Of those patients, 44 were men and six were women, and the average age was 36 years (range 16 to 65 years). Thirty patients were referred from 25 different hospitals. These findings portrayed a young patient base that was distributed all around the province. The peripheral institutions were an average of $110 \mathrm{~km}$ from the replantation centre, with a maximum distance of $140 \mathrm{~km}$. However, one patient was transferred by air from a remote hospital $575 \mathrm{~km}$ from the replant centre.

The average length of time from injury until administration of anesthesia for patients referred from outlying hospitals was $6 \mathrm{~h} 21 \mathrm{~min}$ (Table 1). In contrast, patients who came directly to the replant centre waited $3 \mathrm{~h} 40 \mathrm{~min}$ before surgery began (Table 2).

\section{DISCUSSION}

The results indicate that systemic changes are needed in the treatment and triage of potential candidates for replantation in Quebec. There must be a full spectrum of changes that address the central restraints to an effective, efficient and successful system that provides maximum quality of care to amputee victims. Four segments of the replantation service should be addressed in the change model: province-wide awareness; a centralized system that coordinates the microsurgical teams and replantation centres; the amputation protocol of the ambulance services; and the individual replantation centre's funding for, and organization of, replant treatment and operating room resources.

Microsurgical teams need to maintain their replantation skills by performing microsurgical replantation surgeries throughout the year. Moreover, according to senior members of the Quebec Association of Plastic Surgeons, there were only 10 plastic surgeons who had performed microsurgical replantations, with the majority of microsurgical replantations being performed by a handful of surgeons in 2002. With these trained surgeons scattered around the province, some of them never get the opportunity to operate. As well, few of the institutions where these surgeons practice are equipped to handle microsurgical replantations. Therefore, there is a clear need for systematic change in the organization of replantation surgeons and facilities. A feasible solution to this predicament is the designation of replantation centres and the introduction of a replantation telephone service. The telephone service may direct attending physicians in the referring hospital where to send the amputee victims. The service could have a list of the hospitals capable and willing to operate on these patients, and would have a specific protocol outlined to channel these patients to the centres with the capacity and resources at that time. By outlining specific replantation centres, a critical mass of surgeons and patients could be aligned. The surgeons would benefit from the increase in cases that they perform and therefore maintain their skills. Similarly, the patients would benefit because of the reduced delay in the referring hospitals due to the telephone system assisting them in their transfer.

Another component of the replantation system that requires further consideration is the emergency transport system. A specified ambulance protocol for traumatic amputations that has the ambulances transport the amputee victims from the scene of the accident to the nearest replantation centre would likely increase the success rate of replantation by eliminating the delays in referring hospitals that do not treat these patients. As well, by furnishing the paramedics with specific guidelines that outline the exact procedures to treat and transfer the patients effectively, patient care would be expedited and improved.

As for delays within the emergency room of the replant centre, it is evident that the operating rooms were unable to meet the demand due to insufficient physical and human resources. The institution was not equipped to handle additional emergency operations, and therefore significantly contributed to the delay in the replantation system. Dedicated funding for emergency procedures and operating room improvement is necessary to adequately provide services when 
needed. As well, the aforementioned replantation telephone line could connect emergency doctors with a replantation coordinator who may contact the microsurgical teams, secure an operating room, and assemble the operating room staff and anesthetist promptly in anticipation of the patient's arrival. With proper funding, human resources and clear guidelines, traumatic amputation victims would have improved chances of successful replantation.

\section{CONCLUSION}

Two major bottlenecks to rapid microsurgical replantation were identified. The delay may be attributed to a poorly defined treatment corridor that transfers patients to institutions capable of performing replantation surgery. Moreover, the delay from emergency room to operating room was most often due to operating rooms functioning above capacity without sufficient reserve to acutely provide needed services. Replantation protocols should be established and specific guidelines must be outlined for both primary hospital and prehospital care. Furthermore, a more efficient and cost-effective method of delivering microsurgical replantation care within individual microsurgery centres requires a dedicated allocation of sufficient resources so that the centre can be more responsive to the replantation needs of its constituent patient population. Further studies are required for the evaluation of transport protocols for rural trauma (6). Finally, with the advent of the Quebec Replant Centre subsequent to this study, there have been many changes to the Quebec replantation system. A further study comparing the new system with the old is needed to help identify what factors have positively contributed to the care of replantation patients. Delays to prompt microsurgical replantation are not isolated to Quebec, and therefore, any data gathered from the Quebec model may prove useful in the design of other replantation systems in Canada.

ACKNOWLEDGEMENT: The present research was presented at the 2003 Canadian Society of Plastic Surgeons annual meeting in Whistler, British Columbia, and at the 2003 Quebec Association for Plastic Surgery annual meeting in Hull, Quebec.

\section{REFERENCES}

1. Young JS, Bassam D, Cephas GA, Brady WJ, Butler K, Pomphrey $\mathrm{M}$. Interhospital versus direct scene transfer of major trauma patients in a rural trauma system. Am Surg 1998;64:88-91.

2. Schwartz RJ, Jacobs LM, Yaezel D. Impact of pre-trauma center care on length of stay and hospital charges. J Trauma 1989;29:1611-5.

3. Abernathy JH III, McGwin G Jr, Acker JE III, Rue LW III. Impact of a voluntary trauma system on mortality, length of stay, and cost at a level I trauma center. Am Surg 2002;68:182-92.

4. Nathens AB, Maier RV, Brundage SI, Jurkovich GJ, Grossman DC. The effect of interfacility transfer on outcome in an urban trauma system. J Trauma 2003;55:444-9.

5. Strauch B, Greenstein B, Goldstein R, Liebling RW. Problems and complications encountered in replantation surgery. Hand Clin 1986;2:389-99.

6. Sampalis JS, Denis R, Frechette P, Brown R, Fleiszer D, Mulder D. Direct transport to tertiary trauma centers versus transfer from lower level facilities: Impact on mortality and morbidity among patients with major trauma. J Trauma 1997;43:288-95. 